DEPARTMENT OF THE INTERIOR

U.S. GEOLOGICAL SURVEY

\title{
STRENGTH MEASUREMENTS OF HEATED ILLITE GOUGE AT LOW AND HIGH PORE PRESSURES
}

by

D. E. Moore, R. Summers, and J. D. Byerlee ${ }^{1}$

\author{
Open-File Report $86-578$
}

This report is preliminary and has not been reviewed for conformity with U.S. Geological Survey editorial standards and stratigraphic nomenclature. Any use of trade names is for descriptive purposes only and does not imply endorsement by the USGS.

1 U.S. Geological Survey, 345 Middlefield Road Menlo Park, California 94025 
INTRODUCTION AND EXPERIMENTAL PROCEDURE

This report presents the stress-strain charts for a series of triaxial friction experiments on heated illite gouge. These results comprise the data set for Moore et al. (in preparation). Because of length considerations, only selected strength data are presented in that paper.

The experimental assembly, shown in Figure 1, is similar to other hightemperature designs for triaxial strength tests (e.g., Stesky et a1., 1974; Lockner et a1., 1982). The sample consisted of a layer of gouge $0.65 \mathrm{~mm}$ in thickness sandwiched between $30^{\circ}$ finely ground sawcut surfaces in a granite cylinder $19.0 \mathrm{~mm}$ in diameter and $41.3 \mathrm{~mm}$ long. The gouge-filled cylinder was placed within an annealed copper jacket between titanium carbide end plugs and Lucalox insulators. The space between the copper-jacketed sample and the surrounding resistance heater was loosely packed with boron nitride, which is a good thermal and a poor electrical conductor.

Pore fluids were introduced to the sample along a central inlet that extended almost to the gouge layer by means of a hole drilled partway through the upper granite cylinder. The sawcut granite pieces were presaturated with deionized water to reduce the time required to equilibrate the pore fluid in the sample. Confining and pore pressures were applied first to the sample. Following that, the temperature was raised to the desired value and held there for $1800 \mathrm{~s}$ before the differential stress was applied. Temperatures were monitored by a thermocouple inserted along the pore pressure inlet. Pressures and strains were computer-controlled and-recorded; force and displacement measurements were made outside the pressure vessel. 
The experiments conducted are summarized in Table 1 . The experiments were run at temperatures of $200^{\circ}, 400^{\circ}$ and $600^{\circ} \mathrm{C}$. Confining and pore pressures varied together, such that the effective pressure was kept constant at $100 \mathrm{MPa}$ (99.9 $\mathrm{MPa}$ in the experiments at $0.1 \mathrm{MPa}$ pore pressure). A few additional experiments were run at $0.1 \mathrm{MPa}$ pore pressure and either 175 or $250 \mathrm{MPa}$ confining pressure. The pore fluid was defonized water, and the maximum fluid pressure tested was $100 \mathrm{MPa}$. The experiments were run at strain rates of $10^{-4} / \mathrm{s}$ and $10^{-6} / \mathrm{s}$, which correspond to average sliding velocities along the sawcut of $4.8 \mu \mathrm{m} / \mathrm{s}$ and $4.8 \times 10^{-2} \mu \mathrm{m} / \mathrm{s}$, respectively. These velocities refer to the average rate at which one granite piece slides past the other along the sawcut. For samples that show stick-slip, velocities within the gouge layer will differ significantly between the stick and slip portions of each cycle.

\section{SUMMARY OF RESULTS AND THEIR SIGNIFICANCE}

Stress-strain plots for the illite experiments in Table 1 are shown in Figures 2-14. The differential stresses supported by the gouge samples after $2 \mathrm{~mm}$ axial compression (or $2.3 \mathrm{~mm}$ slip along the sawcut) are plotted against the pore pressure for the experiments run at or near $100 \mathrm{MPa}$ effective pressure in Figures 15-17. Also included in Figures 15-17 are results for the illite gouge at $3 \mathrm{MPa}$ pore pressure and $100 \mathrm{MPa}$ confining pressure, taken from Moore et al. $(1983,1986)$. The $97 \mathrm{MPa}$ effective pressure of these additional runs is close to the $100 \mathrm{MPa}$ effective pressure of the other experiments, and the strengths are also comparable. The results of these experiments are described briefly below; for additional discussion see Moore et al. (in preparation). 
Frictiona 1 Strength

Several trends are apparent from these diagrams. The illite gouge shows a marked increase in strength with temperature increase; at $600^{\circ} \mathrm{C}$, the gouge supports approximately three times the differential stress that it does at $200^{\circ} \mathrm{C}$. The gouge also supports higher stresses at higher effective pressures (Figures 13-15). Increasing the pore pressure at a constant imposed effective pressure does not alter on the strength of the illite gouge at $200^{\circ} \mathrm{C}$ (Figure 15). There are also no velocity effects at $200^{\circ} \mathrm{C}$. However, at $400^{\circ} \mathrm{C}$ (Figure 16) and $600^{\circ} \mathrm{C}$ (Figure 17), the strength decreases with increasing pore pressure, and the gouge shows somewhat different behavior at the two velocities. At $4.8 \mu \mathrm{m} / \mathrm{s}$ slip rate, the frictional strength of the gouge shows an immediate decrease with pore pressure increase, but at pore pressures above $60 \mathrm{MPa}$ the strength levels off to about $225 \mathrm{MPa}$ at $400^{\circ} \mathrm{C}$ and $280 \mathrm{MPa}$ at $600^{\circ} \mathrm{C}$. At $4.8 \mathrm{x}$ $10^{-2} \mu_{m} / s$, the gouge strength is unaffected by pore pressure increase to about $30 \mathrm{MPa}$ and then decreases somewhat irregularly at higher pore pressures.

The strength behavior is attributed to the compaction and welding of the gouge, which cause significant reductions in permeability and porosity. At low pore pressures, this lithification process leads to strength increases. At high pore pressures, large excess pore pressures are generated in the gouge layer during heating, owing to a combination of reduced pore space, claymineral dehydration, and high-temperature expansivity of the pore fluids. Because of the reduced permeability, the excess pressures are only slowly alleviated, thereby causing short-term strength reductions. The high-porepressure experiments at the slower velocity have in effect longer equilibration times, and their strengths are correspondingly higher. 
Sliding Behavior and Correlation with Deformation Textures

The illite gouge shows a greater tendency to stick-slip movement at higher temperatures and at lower pore pressures, effective pressures, and sliding velocities. The average size of the stress drops was also higher at higher temperatures and lower velocities. A series of deformation styles (Figure 18) was identified in the gouge run products that can be correlated with the sliding behavior. At one extreme (texture a), the entire gouge layer shows deformation features, including kink bands and stretched grains. These run products do not contain any shear bands, however, and the samples all slid stably during the experiments. Moving from textures $b$ to $d$ in Figure 18, one sees the progressive localization of slip along a few shear bands that crosscut the gouge layer ( $R 1$ shears) or that occur along the boundary with the granite cylinder (boundary shears). As the shear bands become more prominent, the remaining gouge layer shows fewer and fewer deformation effects. In texture d samples, the gouge outside the shear bands is completely undeformed. The samples containing we11-developed shear bands showed stick-slip behavior when the angle that the Rl shears made with the boundary shears was also relatively high (above $10-14^{\circ}$ ). These textural differences suggest that inhomogeneous stress distributions combined with high-angle $R l$ shears are required for stick-slip motion. The concentration of slip along a few shear planes in the gouge layer creates the potential for large, localized stress build-ups if motion in these zones is impeded. The high Rl shear angles may provide the impediment by inhibiting the transfer of slip between the boundary and Rl shears.

The fracture patterns observed in natural fault zones (e.g., Wallace, 1973; Wallace and Roth, 1967; Sibson, 1986) are very similar to the shear band orientations observed in the experiments. Because of this, conditions 
promoting stick-slip in the laboratory may be used to predict the location of earthquakes along fault zones. For sheet-silicate-rich gouges, relatively high temperatures, low displacement rates, and low confining and fluid pressures would promote instability of sliding. 
Table 1. Experiments Conducted

\begin{tabular}{|c|c|c|c|c|c|}
\hline Experiment & $\begin{array}{l}\text { Temp. } \\
\left({ }^{\circ} \mathrm{C}\right)\end{array}$ & $\begin{array}{l}\text { Velocity } \\
\left(\mu_{\mathrm{m}} / \mathrm{s}\right)\end{array}$ & $\begin{array}{l}\text { Pore } \mathrm{Pr} . \\
(\mathrm{MPa})\end{array}$ & $\begin{array}{c}\text { Conf. Pr. } \\
(\mathrm{MPa})\end{array}$ & $\begin{array}{l}\text { Figure } \\
\text { Numbers }\end{array}$ \\
\hline 1315 & 200 & 4.8 & 10 & 110 & 2,15 \\
\hline 1314 & 200 & 4.8 & 20 & 120 & 3,15 \\
\hline 1313 & 200 & 4.8 & 30 & 130 & 4,15 \\
\hline 1379 & 200 & 4.8 & 40 & 140 & 5,15 \\
\hline 1312 & 200 & 4.8 & 50 & 150 & 6,15 \\
\hline 1376 & 200 & 4.8 & 60 & 160 & 7,15 \\
\hline 1311 & 200 & 4.8 & 70 & 170 & 8,15 \\
\hline 1377 & 200 & 4.8 & 80 & 180 & 9,15 \\
\hline 1316 & 200 & 4.8 & 90 & 190 & 10,15 \\
\hline 1378 & 200 & 4.8 & 100 & 200 & 11,15 \\
\hline 1281 & 200 & 0.048 & 10 & 110 & 2,15 \\
\hline 1282 & 200 & 0.048 & 15 & 115 & 15 only \\
\hline 1283 & 200 & 0.048 & 20 & 120 & 3,15 \\
\hline 1329 & 200 & 0.048 & 30 & 130 & 4,15 \\
\hline 1331 & 200 & 0.048 & 40 & 140 & 5,15 \\
\hline 1328 & 200 & 0.048 & 50 & 150 & 6,15 \\
\hline 1335 & 200 & 0.048 & 60 & 160 & 7,15 \\
\hline 1327 & 200 & 0.048 & 70 & 170 & 8,15 \\
\hline 1334 & 200 & 0.048 & 80 & 180 & 9,15 \\
\hline 1319 & 200 & 0.048 & 90 & 190 & 10,15 \\
\hline 1333 & 200 & 0.048 & 100 & 200 & 11,15 \\
\hline 1362 & 400 & 4.8 & 10 & 110 & 2,16 \\
\hline 1299 & 400 & 4.8 & 20 & 120 & 3,16 \\
\hline 1300 & 400 & 4.8 & 30 & 130 & 4,16 \\
\hline 1361 & 400 & 4.8 & 40 & 140 & 5,16 \\
\hline 1301 & 400 & 4.8 & 50 & 150 & 6,16 \\
\hline 1360 & 400 & 4.8 & 60 & 160 & 7,16 \\
\hline 1302 & 400 & 4.8 & 70 & 170 & 8,16 \\
\hline 1359 & 400 & 4.8 & 80 & 180 & 9,16 \\
\hline 1303 & 400 & 4.8 & 90 & 190 & 10,16 \\
\hline 1358 & 400 & 4.8 & 100 & 200 & 11,16 \\
\hline 1280 & 400 & 0.048 & 10 & 110 & 2,16 \\
\hline 1279 & 400 & 0.048 & 15 & 115 & 16 on $1 y$ \\
\hline 1278 & 400 & 0.048 & 20 & 120 & 3,16 \\
\hline 1277 & 400 & 0.048 & 25 & 125 & 16 on $1 y$ \\
\hline 1276 & 400 & 0.048 & 30 & 130 & 4,16 \\
\hline 1349 & 400 & 0.048 & 40 & 140 & 5,16 \\
\hline 1284 & 400 & 0.048 & 50 & 150 & 6,16 \\
\hline 1348 & 400 & 0.048 & 60 & 160 & 7,16 \\
\hline 1285 & 400 & 0.048 & 70 & 170 & 8,16 \\
\hline 1347 & 400 & 0.048 & 80 & 180 & 9,16 \\
\hline 1287 & 400 & 0.048 & 90 & 190 & 10,16 \\
\hline 1346 & 400 & 0.048 & 100 & 200 & 11,16 \\
\hline
\end{tabular}




\begin{tabular}{|c|c|c|c|c|c|}
\hline Experiment & $\begin{array}{l}\text { Temp. } \\
\left({ }^{\circ} \mathrm{C}\right)\end{array}$ & $\begin{array}{c}\text { Velocity } \\
\left(\mu_{\mathrm{m}} / \mathrm{s}\right)\end{array}$ & $\begin{array}{c}\text { Pore Pr. } \\
(\mathrm{MPa})\end{array}$ & $\begin{array}{c}\text { Conf . Pr. } \\
(\mathrm{MPa})\end{array}$ & $\begin{array}{l}\text { Figure } \\
\text { Numbers }\end{array}$ \\
\hline 1317 & 600 & 4.8 & 10 & 110 & 2,17 \\
\hline 1308 & 600 & 4.8 & 20 & 120 & 3,17 \\
\hline 1307 & 600 & 4.8 & 30 & 130 & 4,17 \\
\hline 1326 & 600 & 4.8 & 40 & 140 & 5,17 \\
\hline 1306 & 600 & 4.8 & 50 & 150 & 6,17 \\
\hline 1325 & 600 & 4.8 & 60 & 160 & 7,17 \\
\hline 1310 & 600 & 4.8 & 70 & 170 & 8,17 \\
\hline 1324 & 600 & 4.8 & 80 & 180 & 9,17 \\
\hline 1304 & 600 & 4.8 & 90 & 190 & 10,17 \\
\hline 1323 & 600 & 4.8 & 100 & 200 & 11,17 \\
\hline 1267 & 600 & 0.048 & 10 & 110 & 2,17 \\
\hline 1270 & 600 & 0.048 & 15 & 150 & 17 on $1 y$ \\
\hline 1269 & 600 & 0.048 & 20 & 120 & 3,17 \\
\hline 1264 & 600 & 0.048 & 25 & 125 & 17 on $1 y$ \\
\hline 1263 & 600 & 0.048 & 30 & 130 & 4,17 \\
\hline 1322 & 600 & 0.048 & 40 & 140 & 5,17 \\
\hline 1290 & 600 & 0.048 & 50 & 150 & 6,17 \\
\hline 1321 & 600 & 0.048 & 60 & 160 & 7,17 \\
\hline 1289 & 600 & 0.048 & 70 & 170 & 8,17 \\
\hline 1320 & 600 & 0.048 & 80 & 180 & 9,17 \\
\hline 1318 & 600 & 0.048 & 90 & 190 & 10,17 \\
\hline 1262 & 600 & 0.048 & 100 & 200 & 11,17 \\
\hline 1291 & 200 & 4.8 & 0.1 & 100 & 12,15 \\
\hline 1367 & 200 & 4.8 & 0.1 & 175 & 13 only \\
\hline 1294 & 200 & 4.8 & 0.1 & 250 & 14 on $1 y$ \\
\hline 1336 & 200 & 0.048 & 0.1 & 100 & 12,15 \\
\hline 1363 & 400 & 4.8 & 0.1 & 100 & 12,16 \\
\hline 1374 & 400 & 4.8 & 0.1 & 175 & 13 on $1 y$ \\
\hline 1297 & 400 & 4.8 & 0.1 & 250 & 14 only \\
\hline 1364 & 400 & 0.048 & 0.1 & 100 & 12,16 \\
\hline 1293 & 600 & 4.8 & 0.1 & 100 & 12,17 \\
\hline 1369 & 600 & 4.8 & 0.1 & 175 & 13 on $1 y$ \\
\hline 1296 & 600 & 4.8 & 0.1 & 250 & 14 on $1 y$ \\
\hline 1365 & 600 & 0.048 & 0.1 & 100 & 12,17 \\
\hline
\end{tabular}




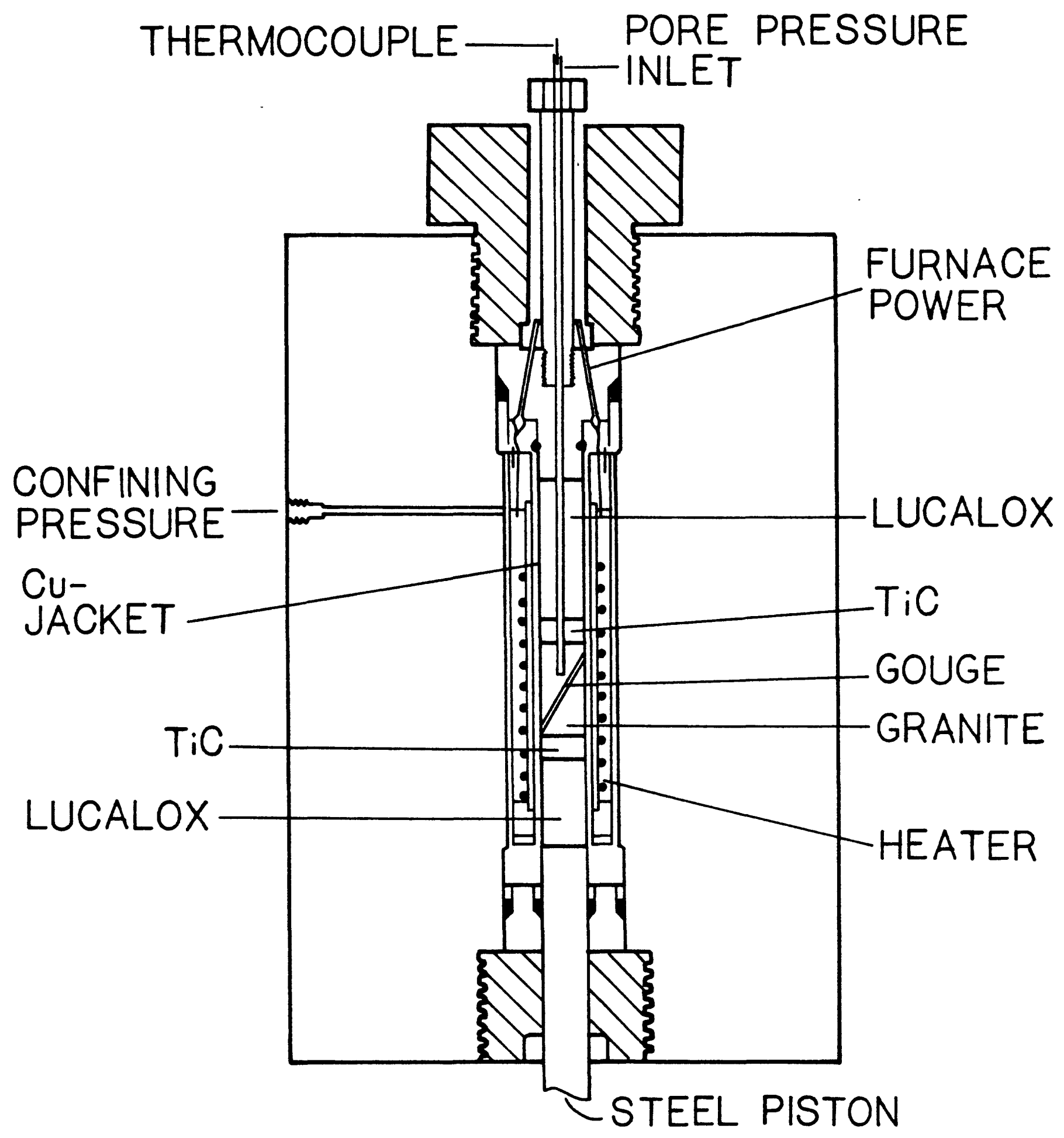

Figure 1. Experimental assembly. 


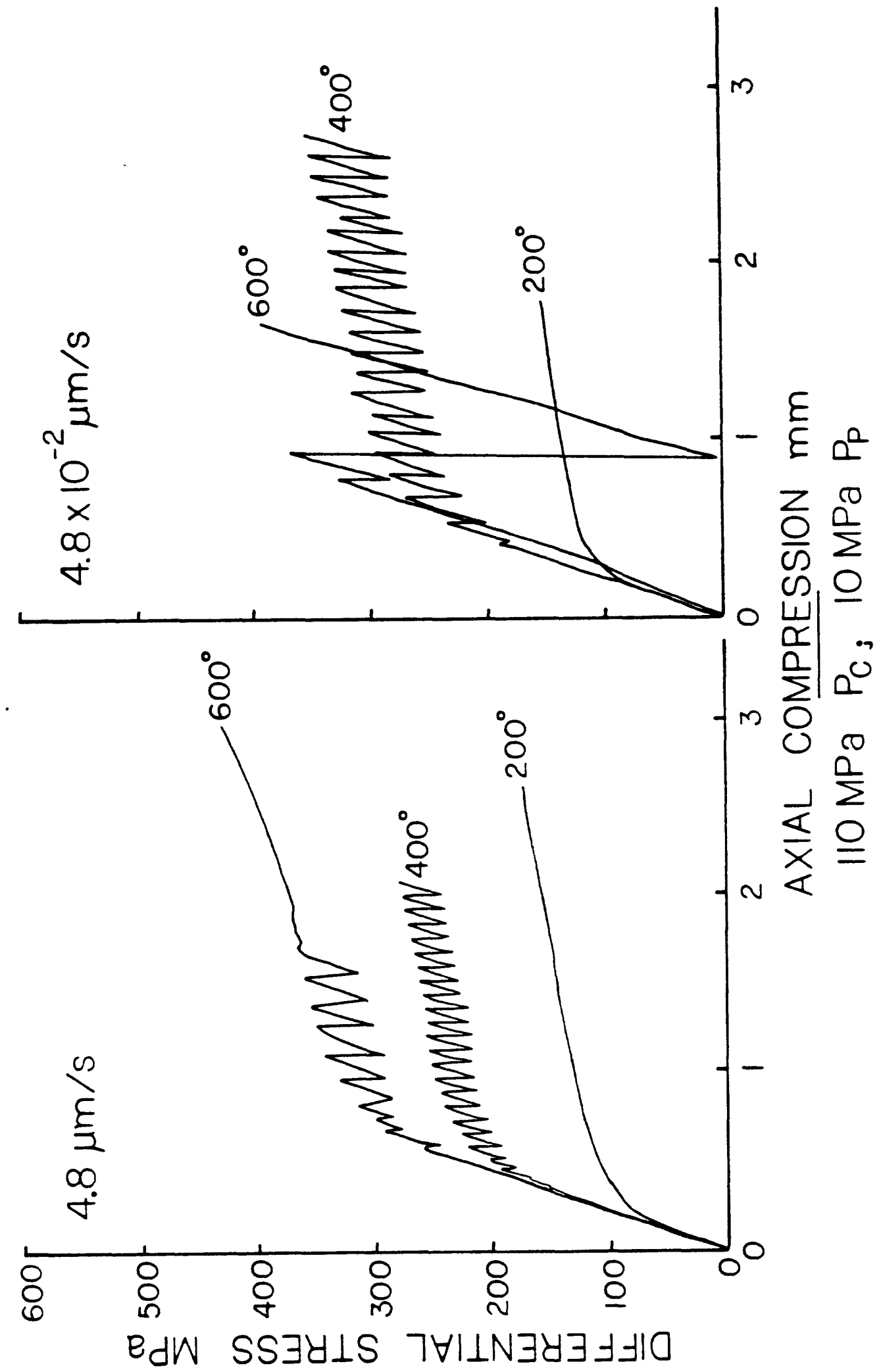

Figure 2. 


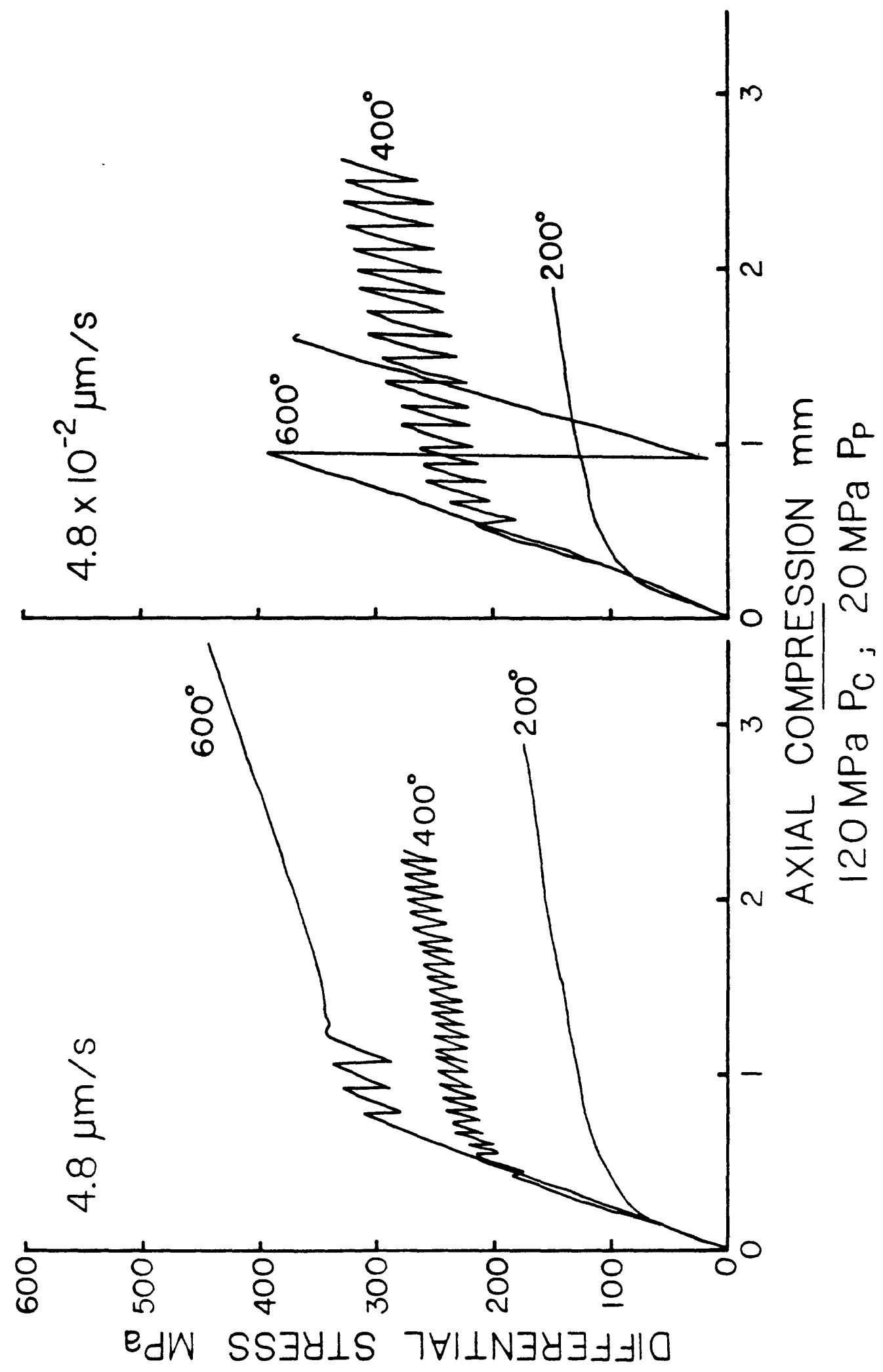

Figure 3 . 


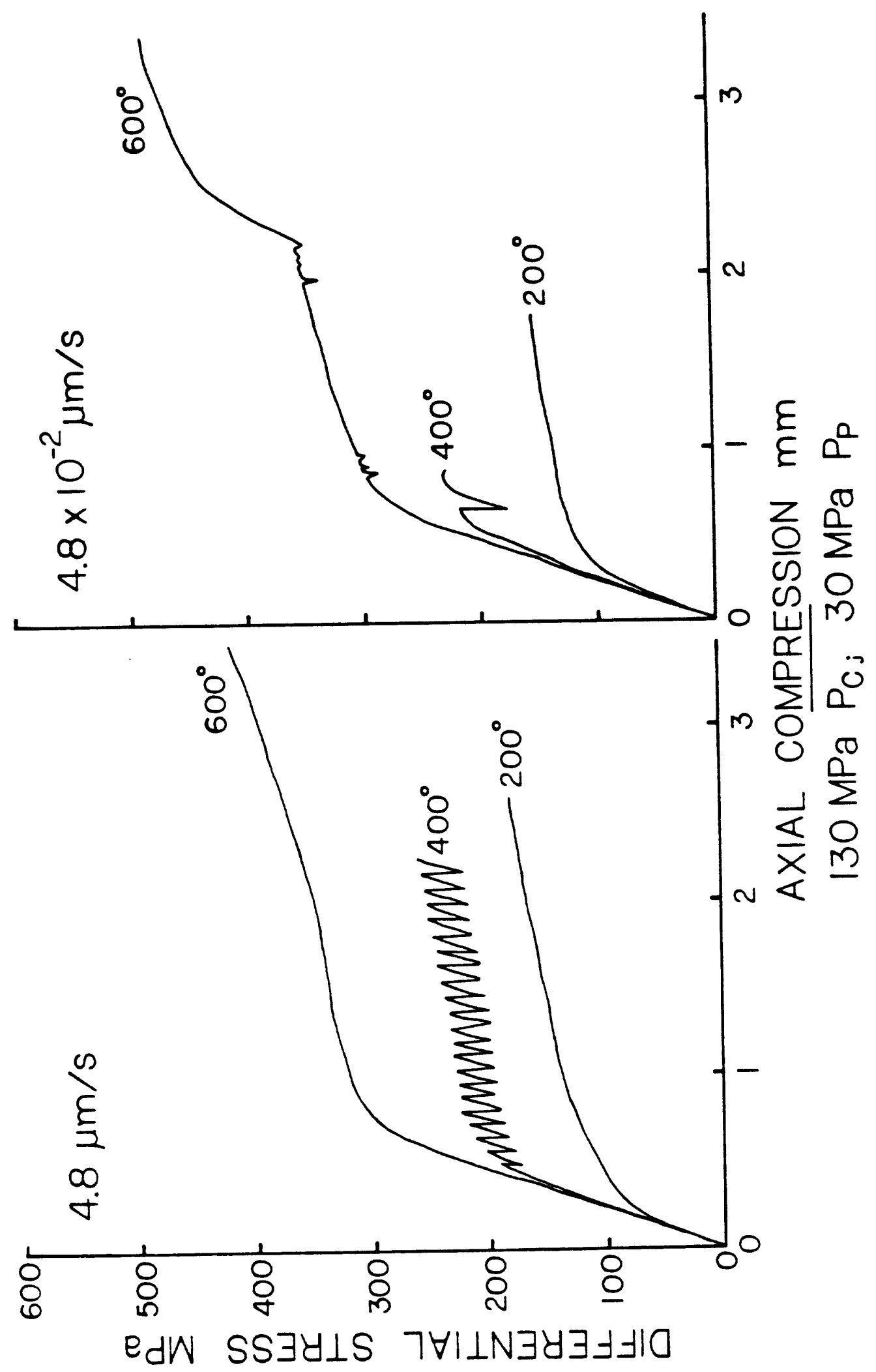

Figure 4. 


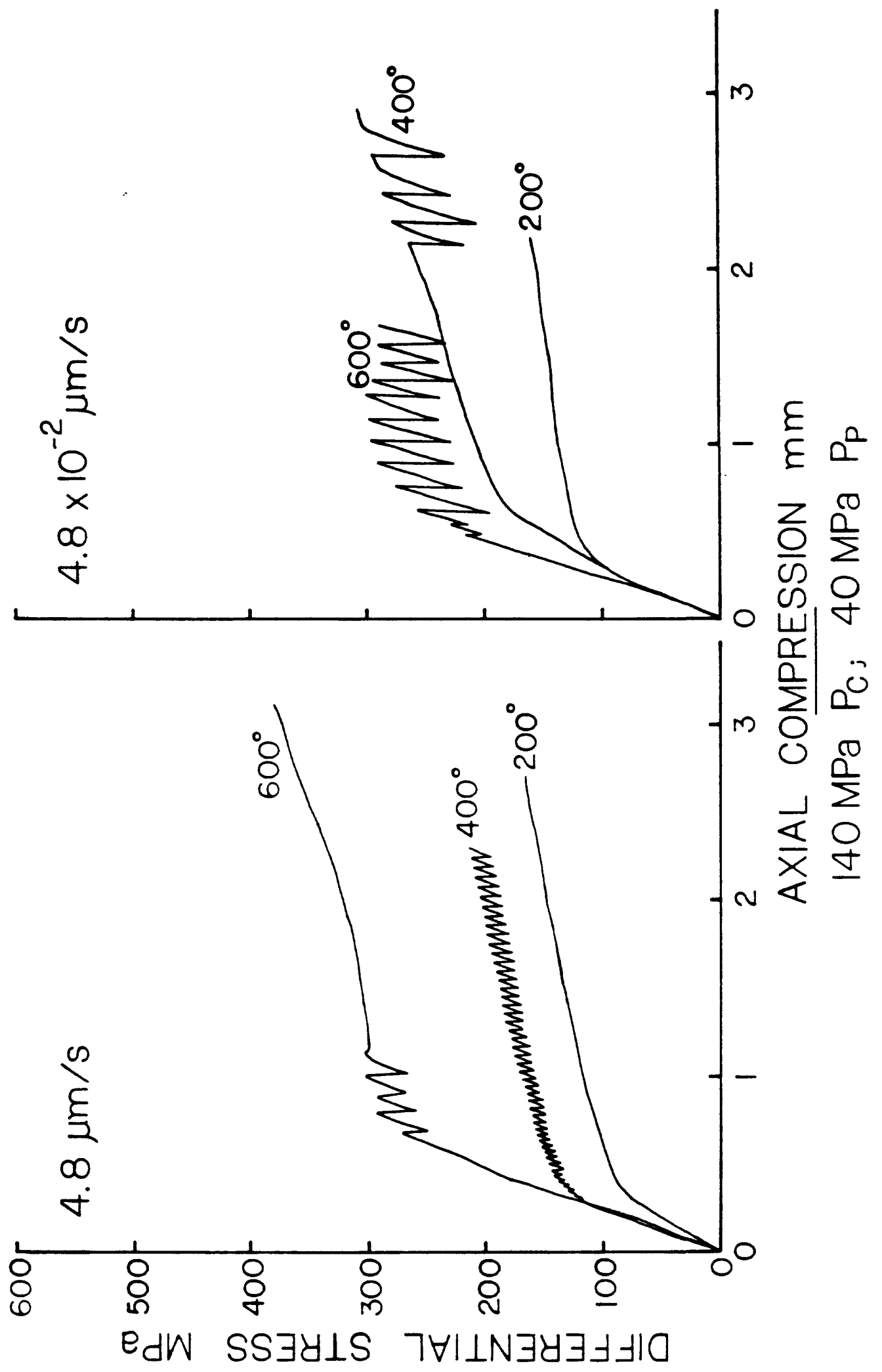

Figure 5 . 


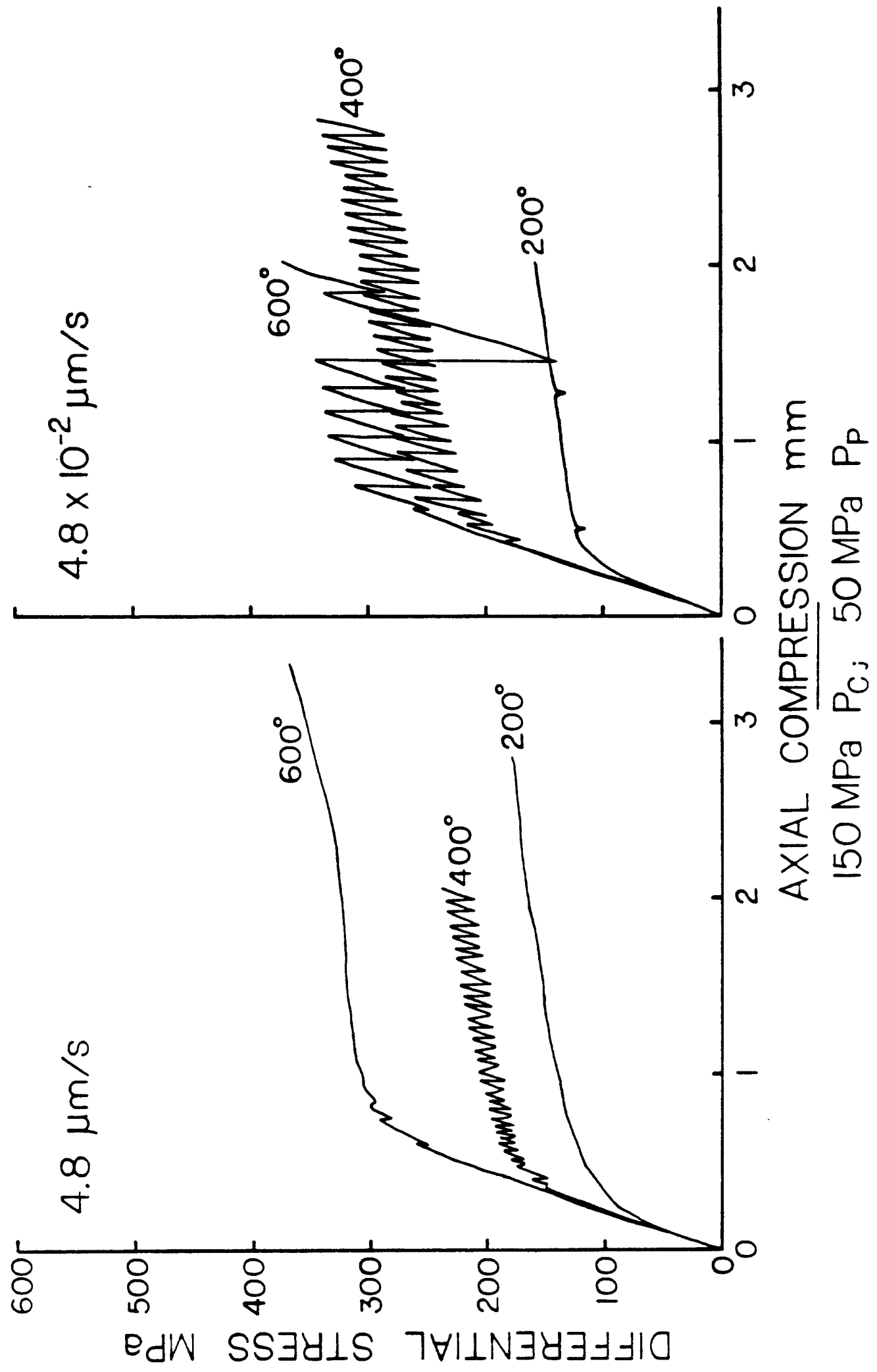

Figure 6 . 


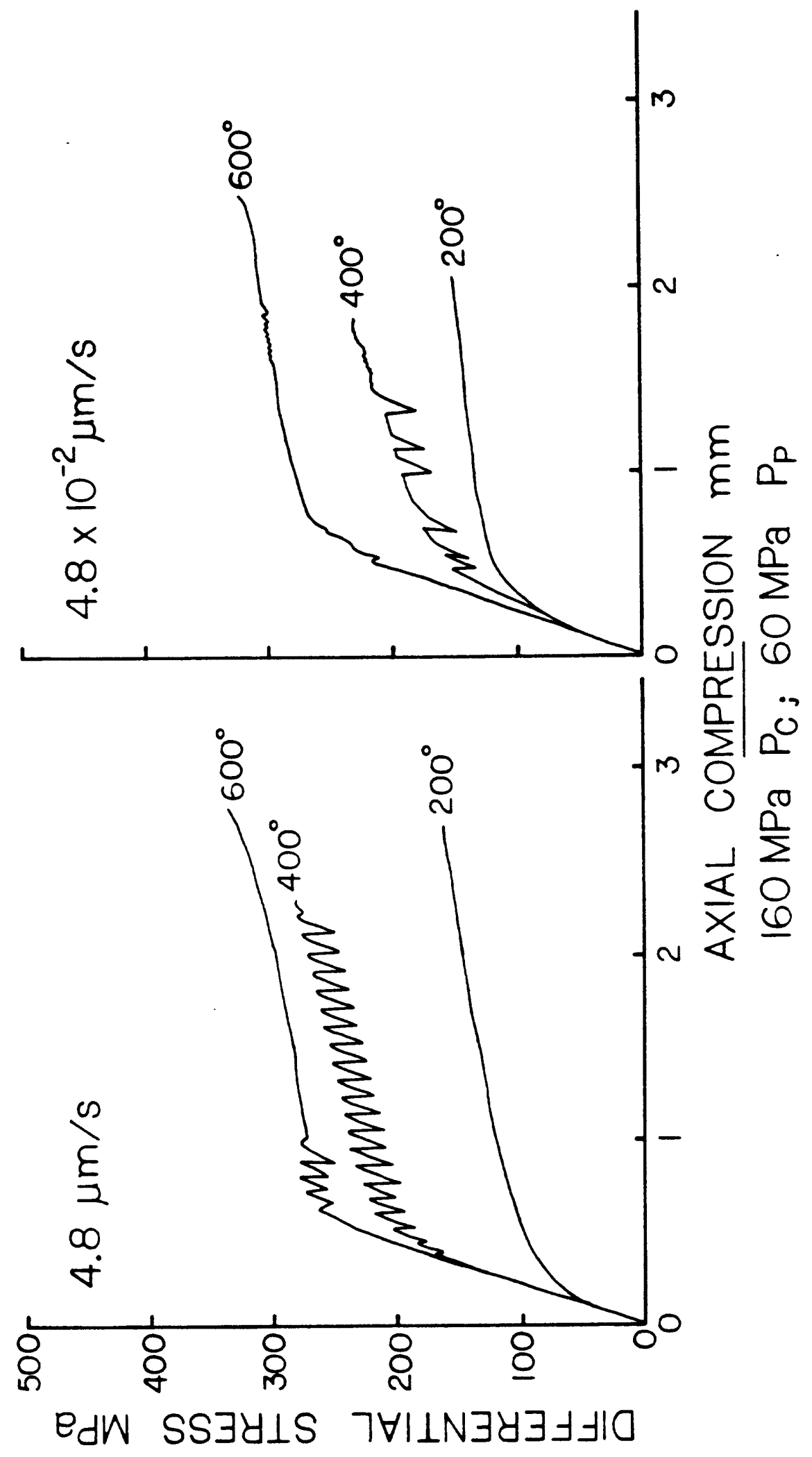

Figure 7 . 


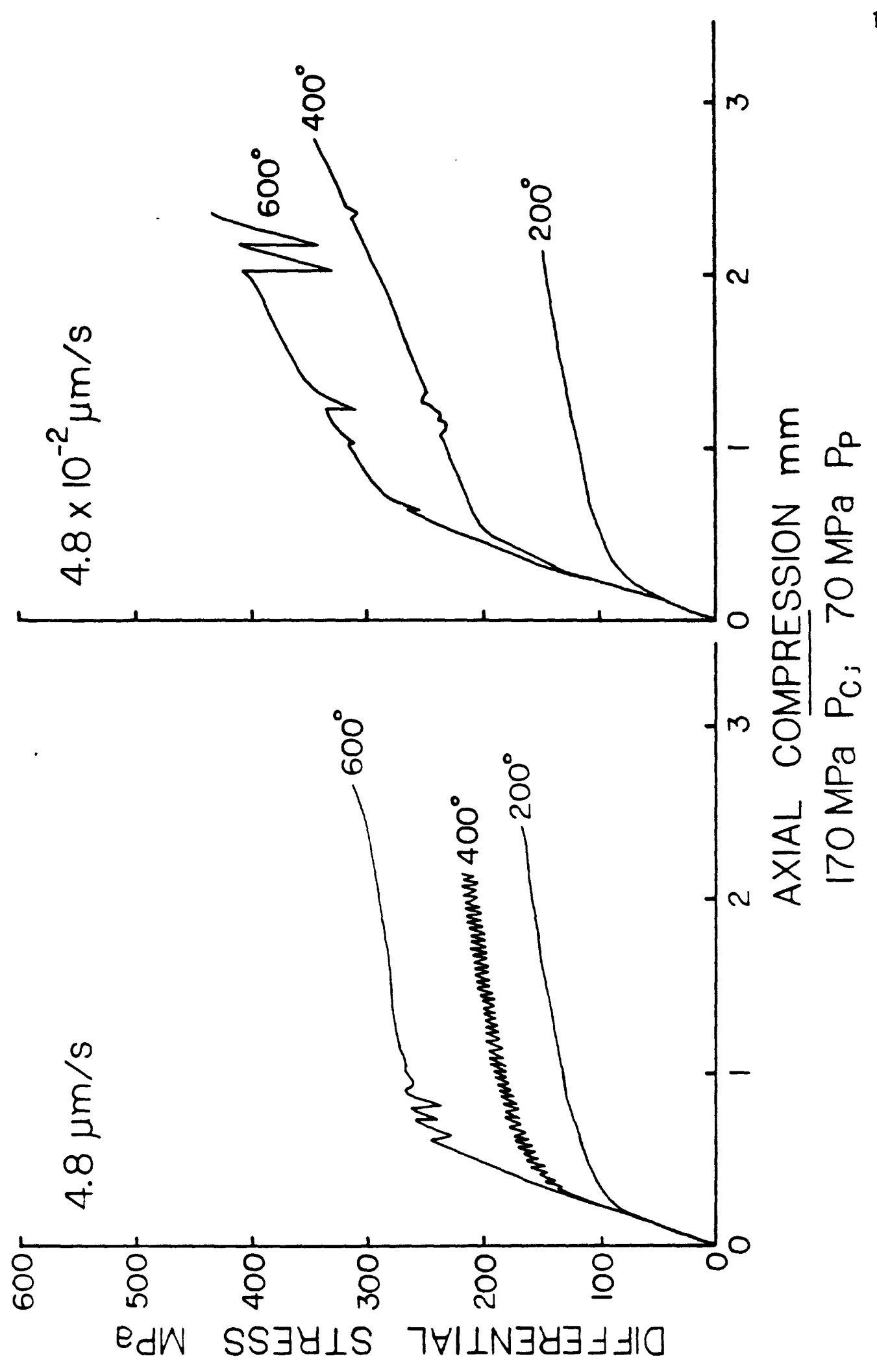

Figure 8. 


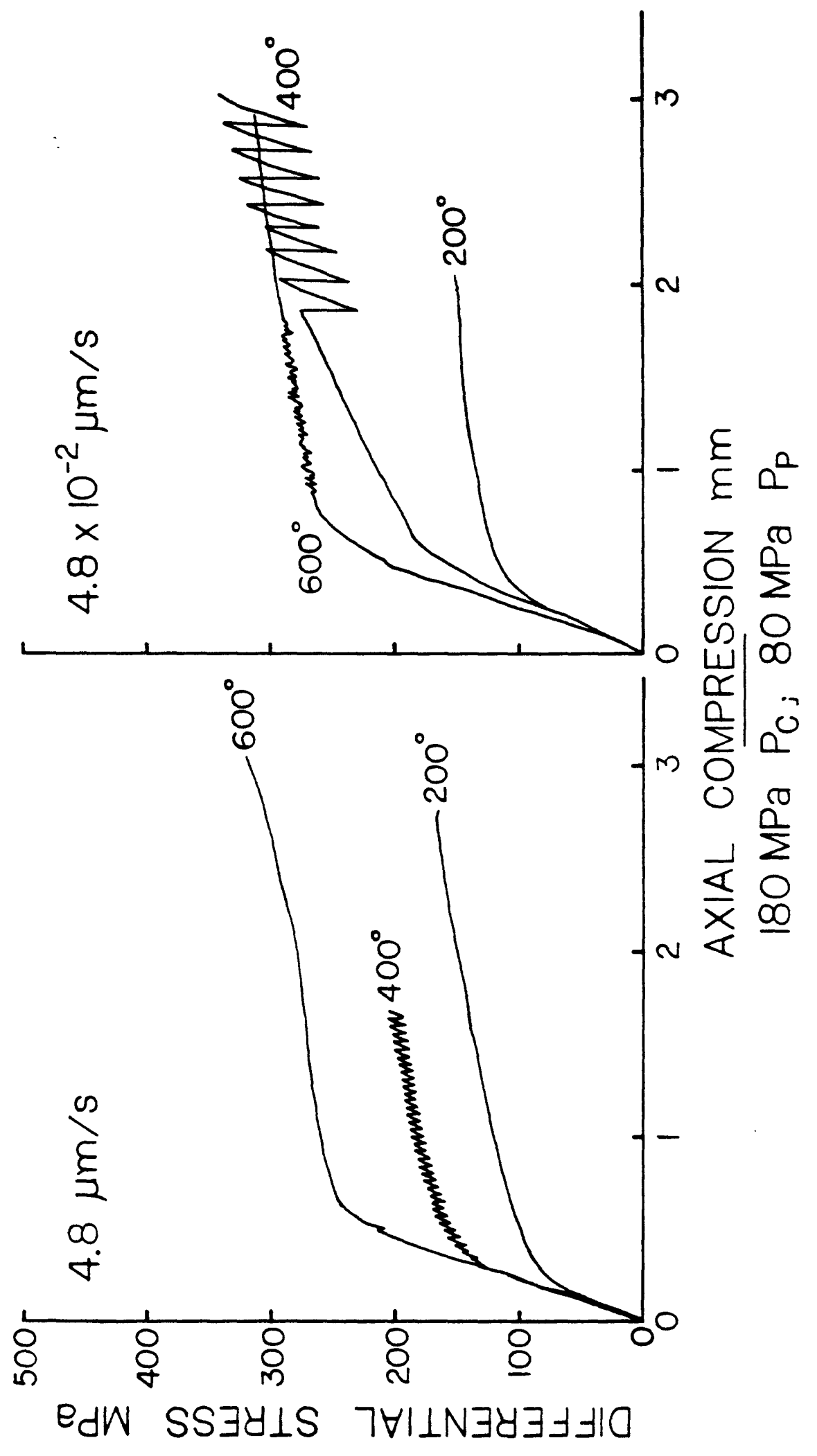

Figure 9. 


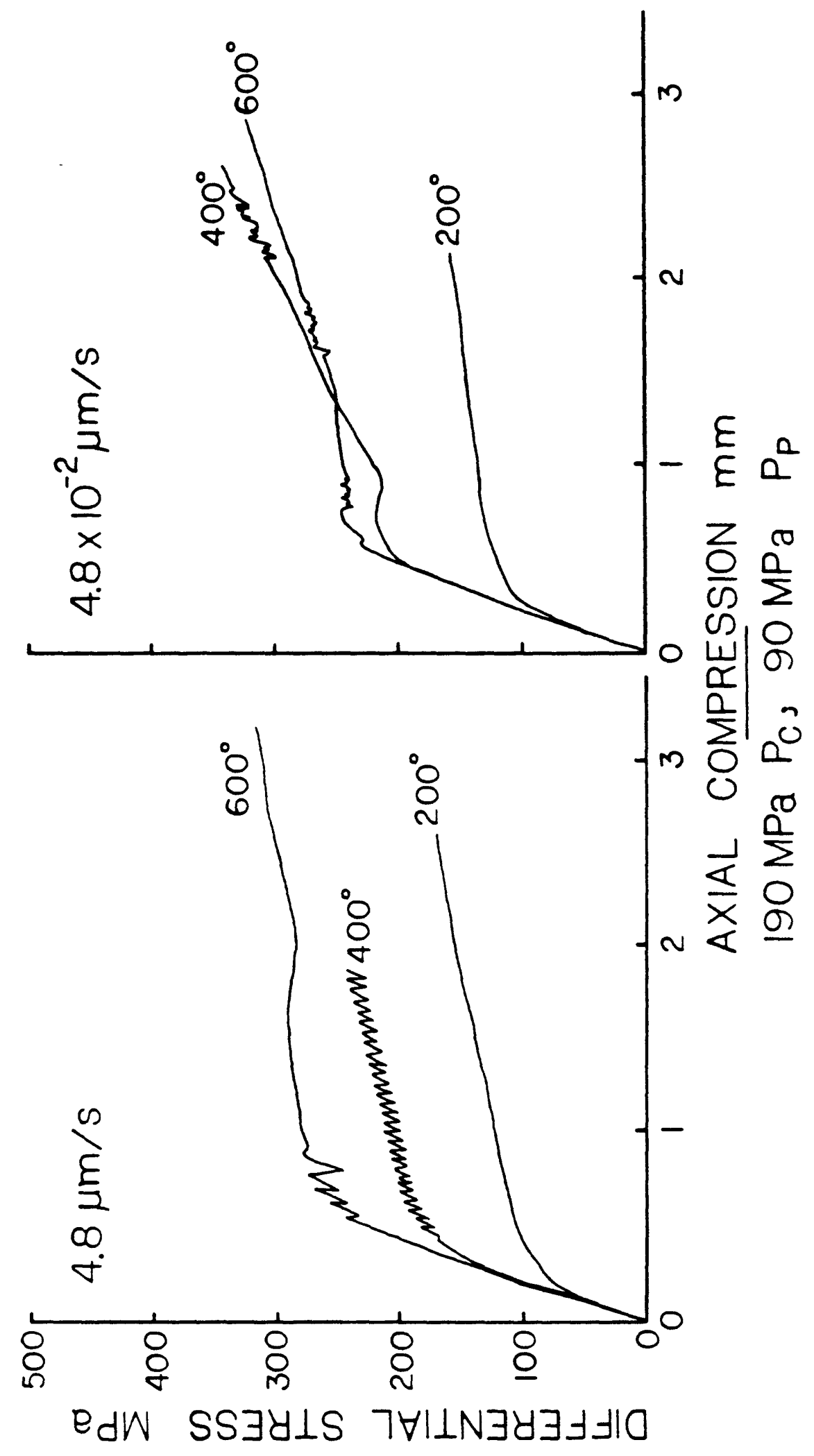

Figure 10. 


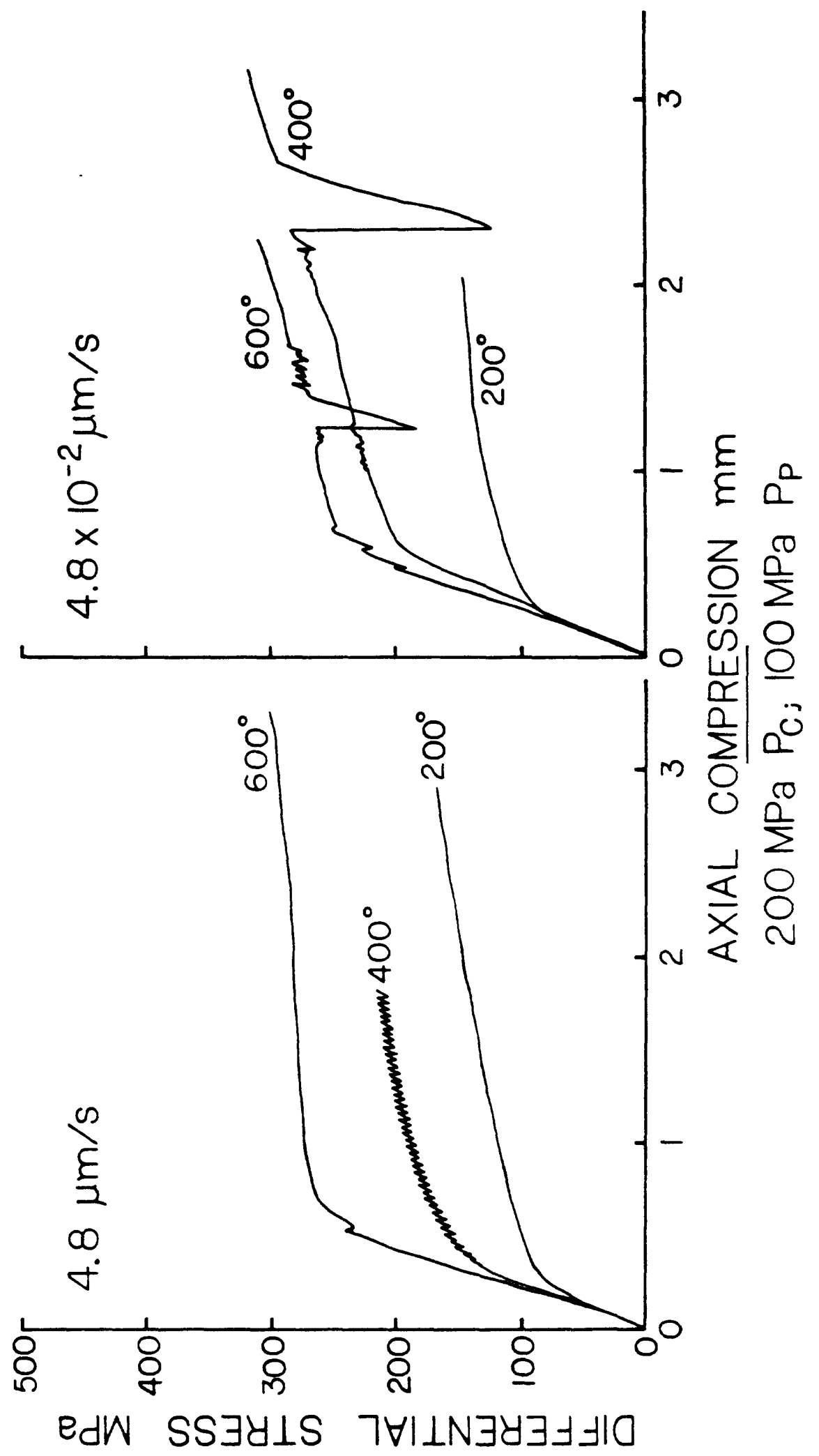

Figure 11. 


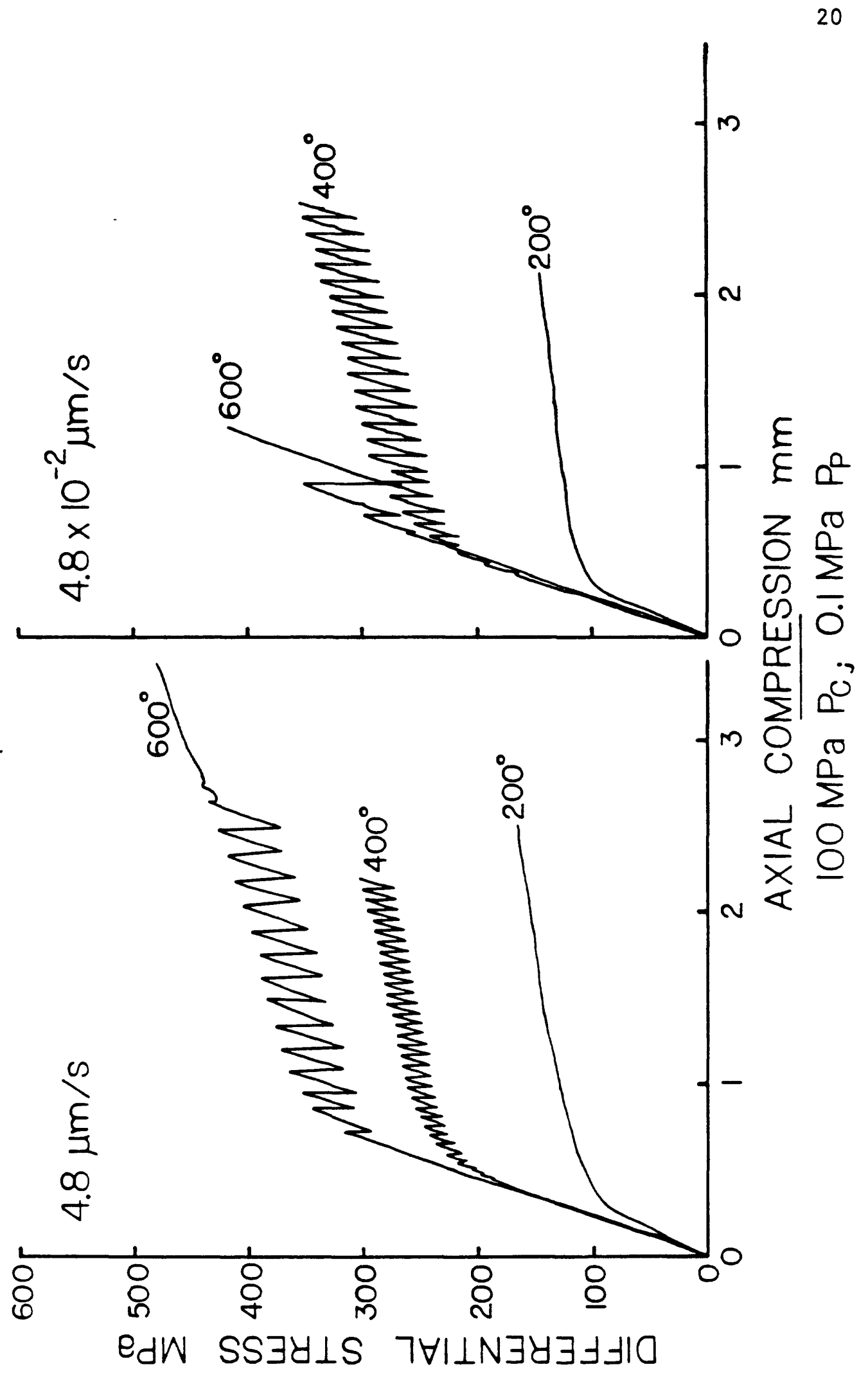

Figure 12 . 


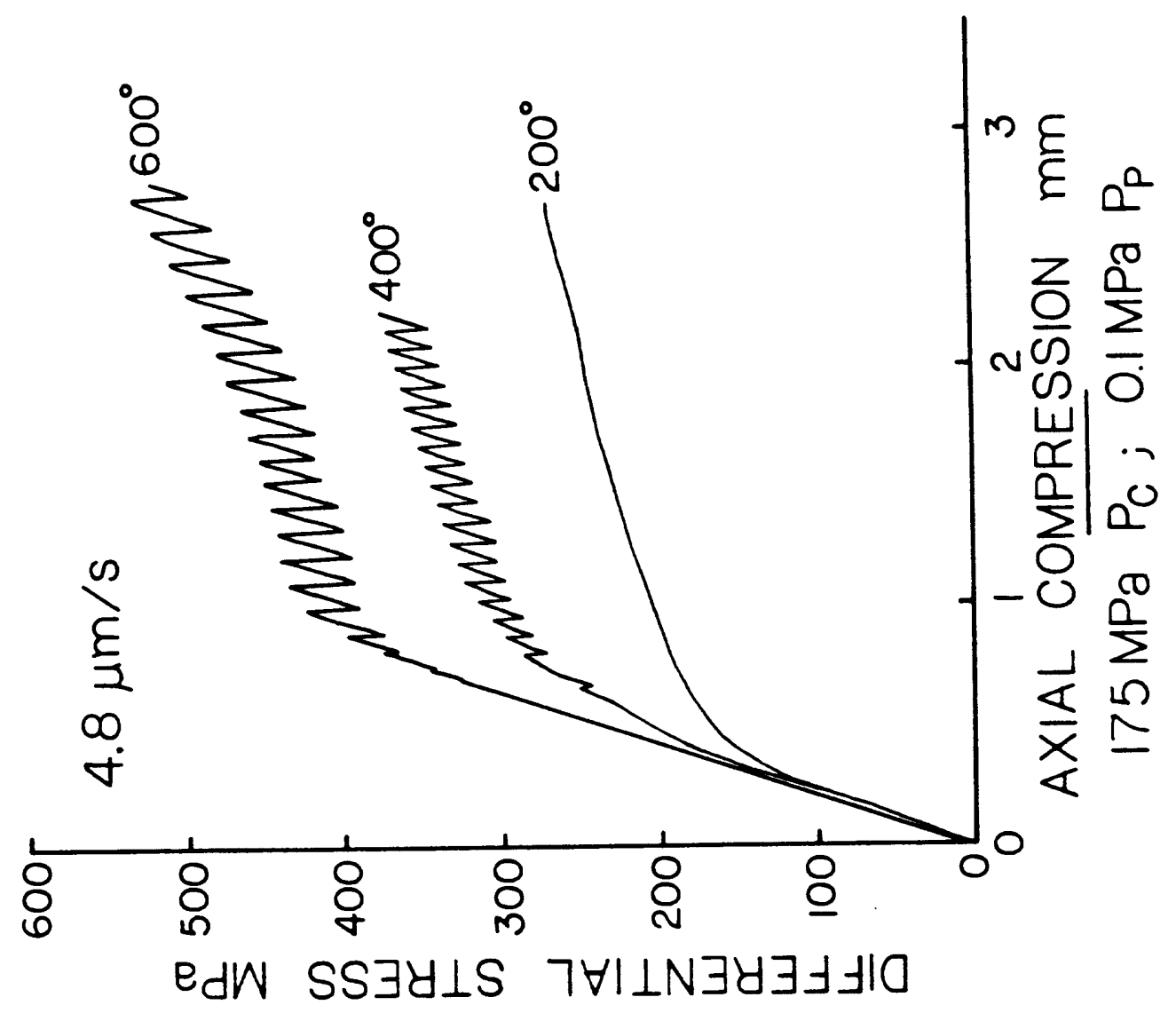

Figure 13. 


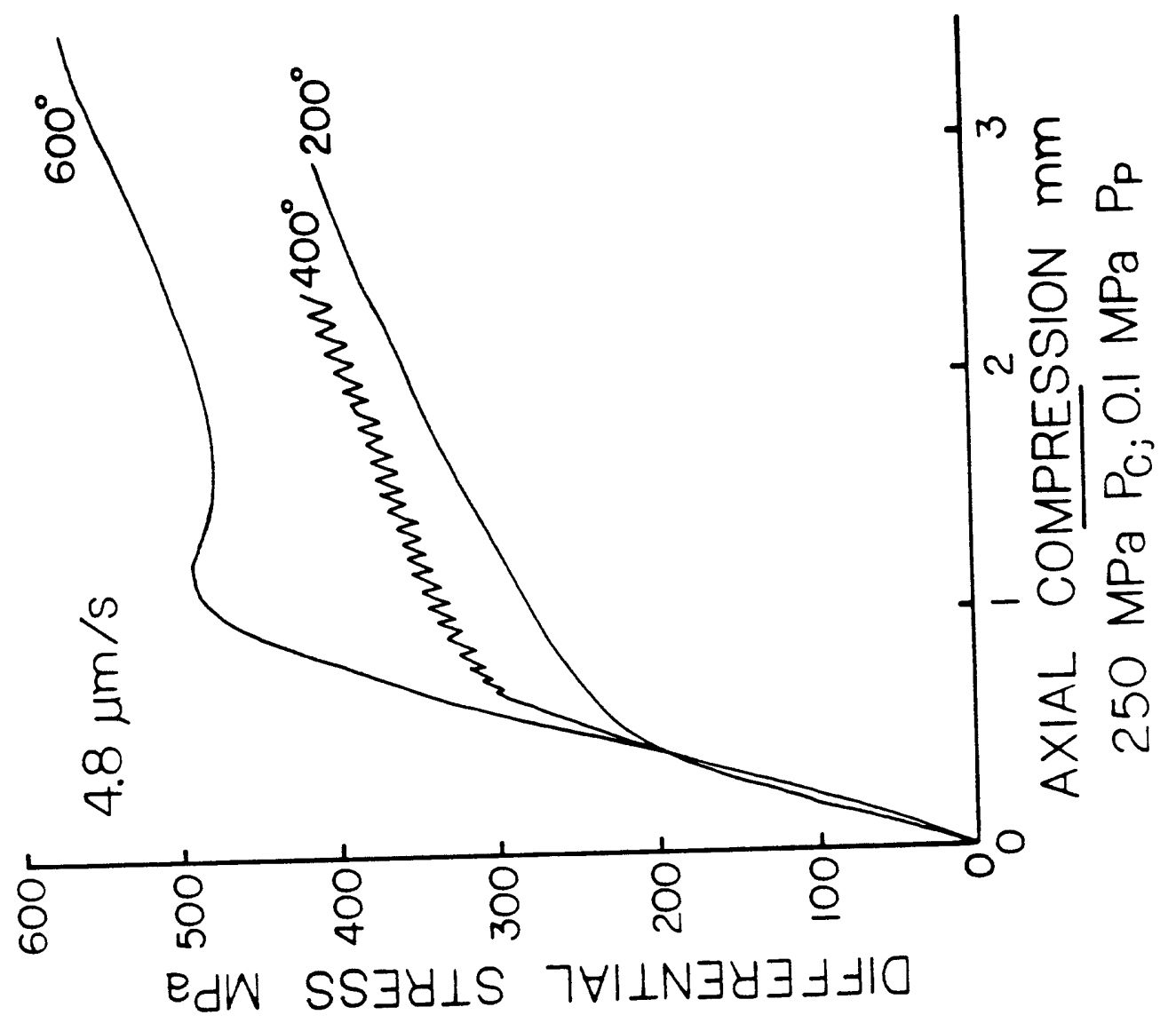

Figure 14. 


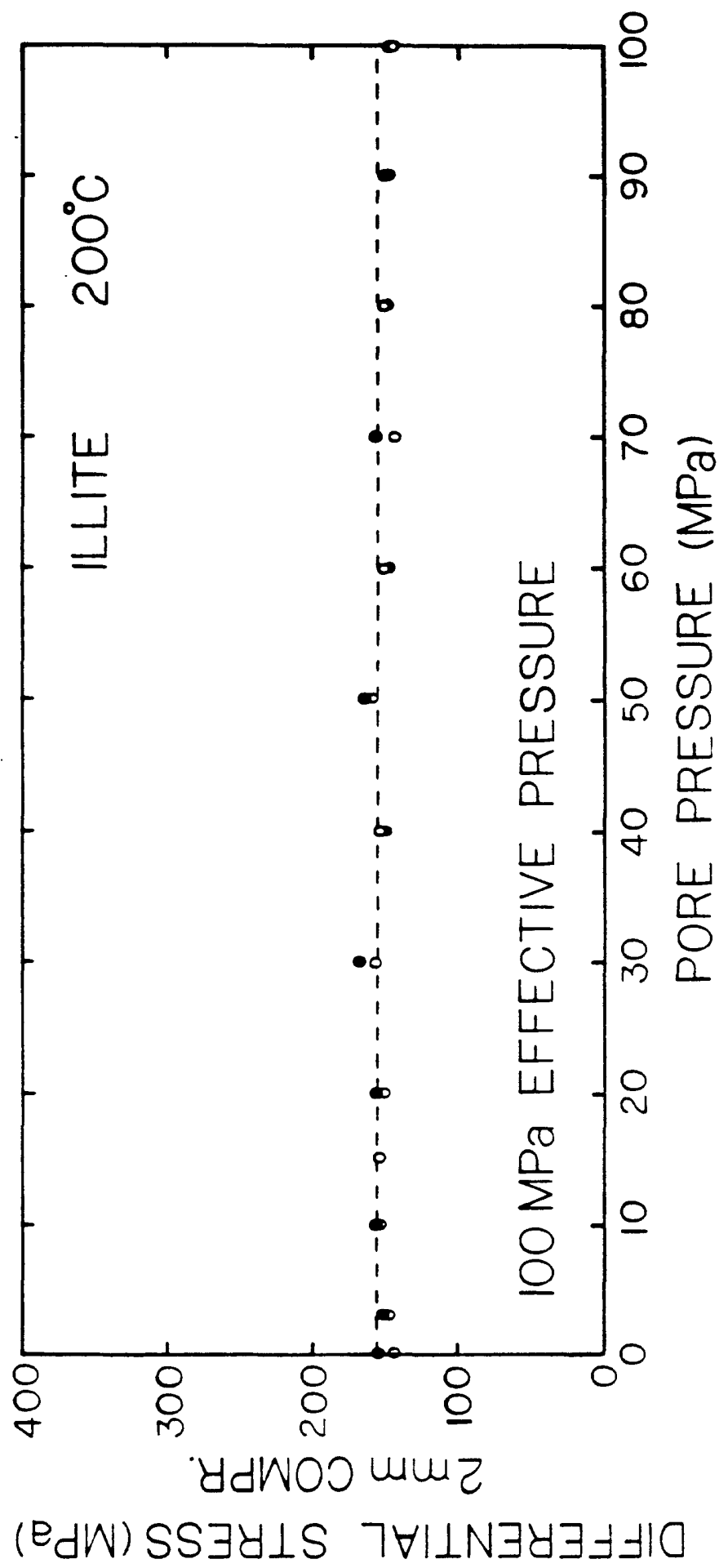

Figure 15. Differential stress after $2 \mathrm{~mm}$ axial compression (or $2.3 \mathrm{~mm}$ slip along the sawcut) for $200^{\circ} \mathrm{C}$ illite experiments. Also included are results at $3 \mathrm{MPa}$ pore pressure and $100 \mathrm{MPa}$ confining pressure from lloore et al. $(1983,1936)$. Open circles represent experiments run at $4.8 \times 10^{-2} \mu \mathrm{m} / \mathrm{s}$ sliding velocity, and filled circles represent experiments at $4.8 \mu \mathrm{m} / \mathrm{s}$. All the points lie close to a dashed line of constant differential stress, at approximately 160 :1Pa. 


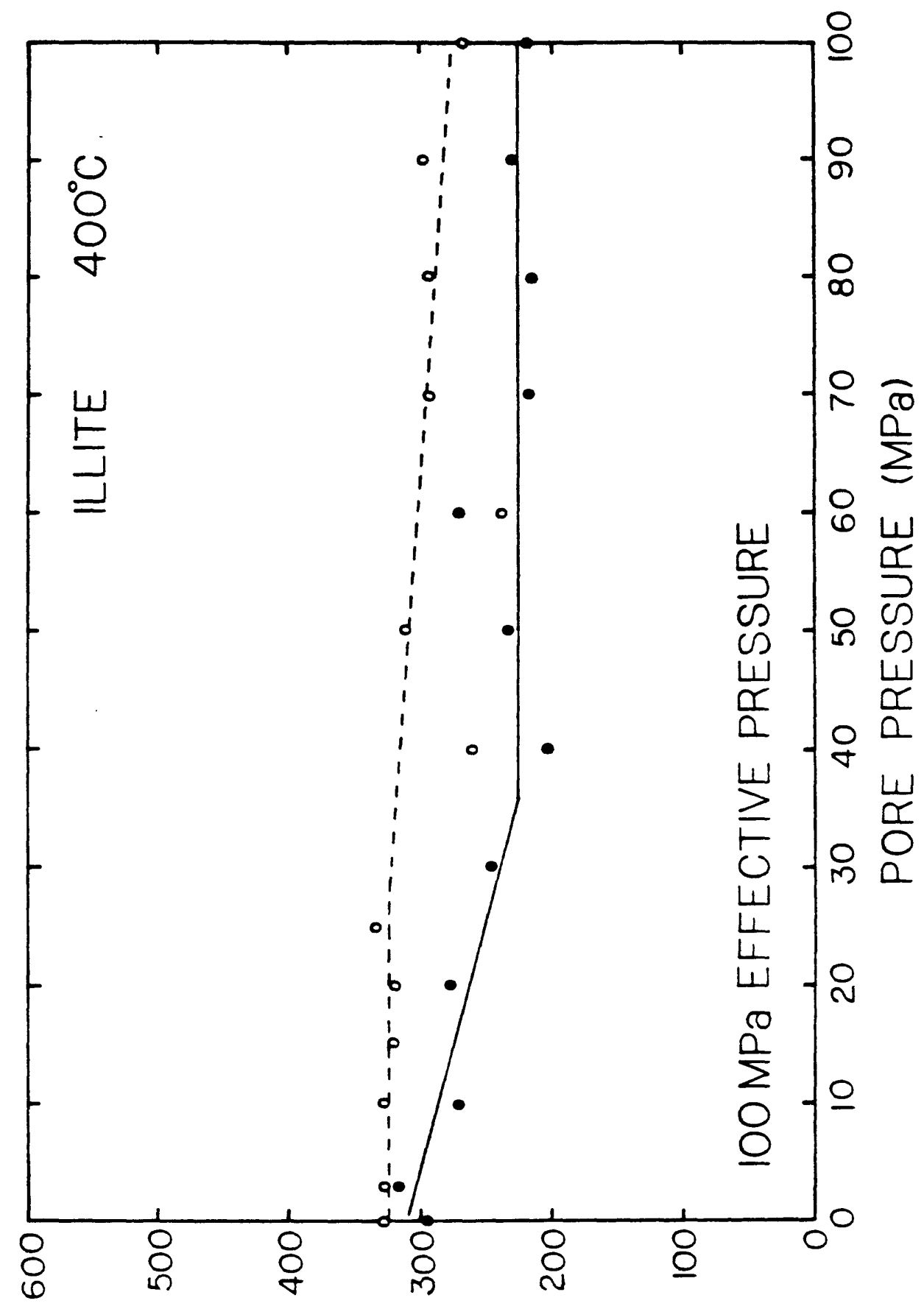

"ydWOOWW "(

Figure 16. Differential stress after $2 \mathrm{~mm}$ axial compression $(2.3 \mathrm{~mm}$ slip along sawcut) for $400^{\circ} \mathrm{C}$ illite experiments. Symbols as in Figure 15. Data at $3 \mathrm{MPa}$ pore pressure are taken from Moore et al. $(1993,1986)$. The solid line connects most of the points for experiments at $4.8 \mu \mathrm{m} / \mathrm{s}$ slip rate, and the dashed line connects most of the points at $4.8 \times$ $10^{-2} \mu \mathrm{m} / \mathrm{s}$ velocity. These lines show the general trends in strength at each velocity. A few of the points at both slip rates have relatively low strengths compared to the other results. 


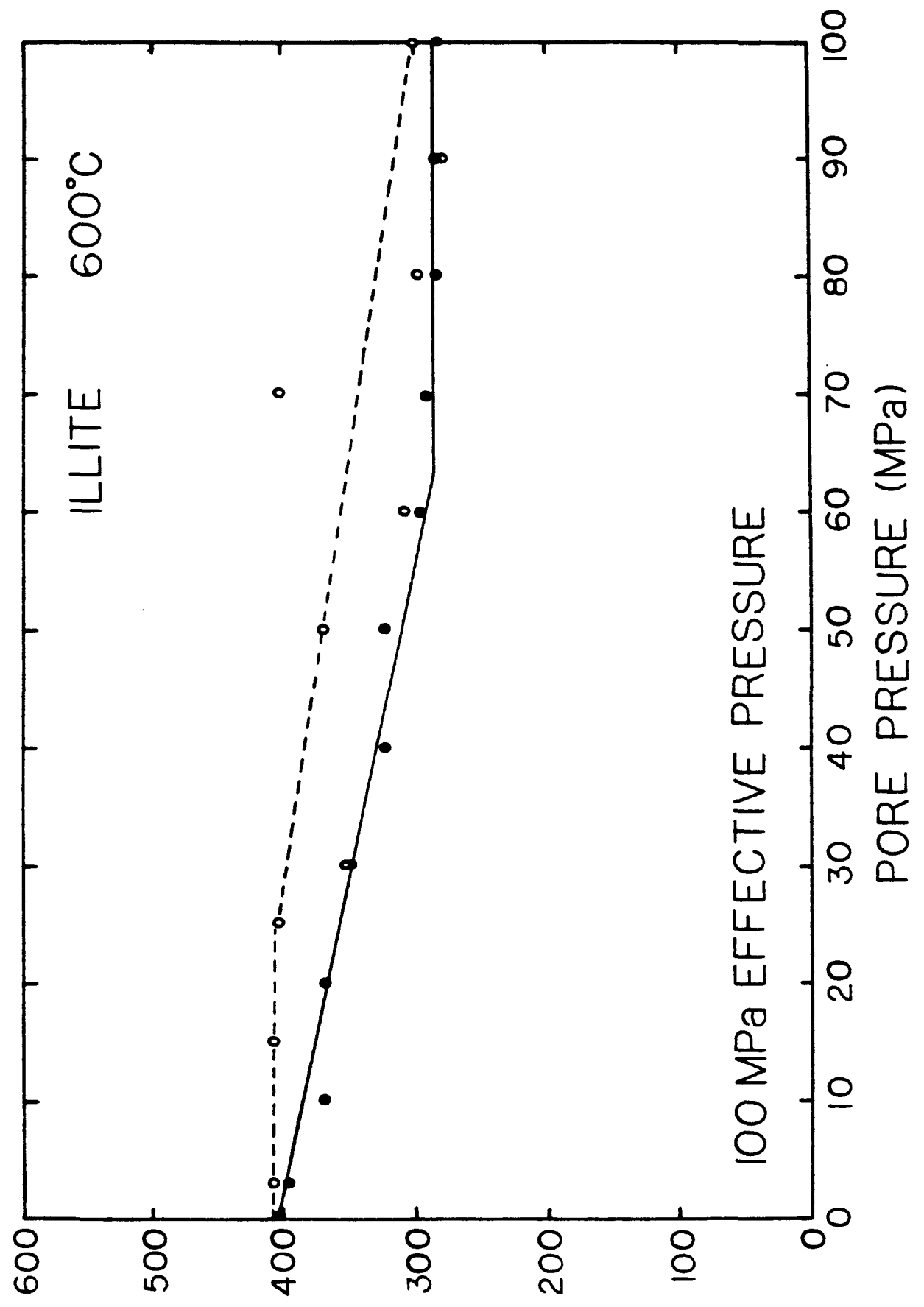

'UdWOJ Umz '(

Figure 17. Differential stress after $2 \mathrm{~mm}$ axial compression $(2.3 \mathrm{~mm}$ slip along sawcut) for illite gouge at $600^{\circ} \mathrm{C}$. Symbols and 1 ines as in Figures 15 and 16. Results at $3 \mathrm{MPa}$ pore pressure from lloore et al. $(1983,1986)$. A few of the experiments at $4.8 \times \frac{10^{-2}}{\mathrm{~m}} / \mathrm{s}$ have relatively low strengths compared to the other results, whereas the experiment at $70 \mathrm{MPa}$ pore pressure has an unusually high strength that is comparable to the results at low pore pressures. 

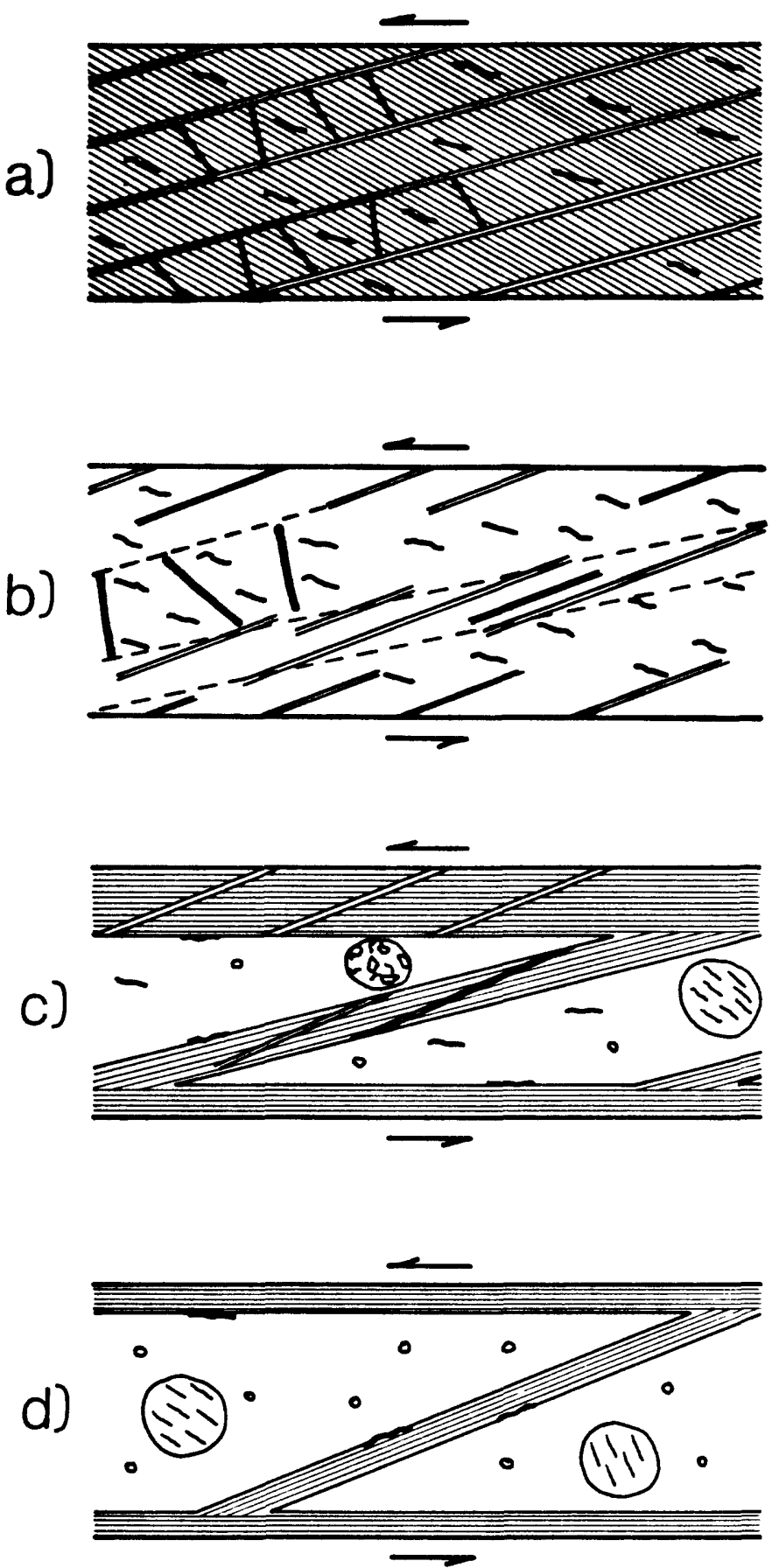

Figure 18. Textural classification of illite gouge run products. 


\section{REFERENCES}

Lockner, D.A., Summers, R., Moore, D., and Byerlee, J.D., 1982. Laboratory measurements of reservoir rock from the Geysers geothermal field, California, International Journal of Rock Mechanics and Mining Sciences and Geomechanics Abstracts 19: 65-80.

Moore, D.E., Summers, R., and Byerlee, J.D., 1983. Strengths of clay and nonclay fault gouge at elevated temperatures and pressures, Proceedings $24 \mathrm{th}$ U.S. Symposium on Rock Mechanics: 489-500.

Moore, D.E., Summers, R., and Byerlee, J., 1986. The effect of sliding velocity on the frictional and physical properties of heated fault gouge, The Interna1 Structure of Fault Zones, C.-Y. Wang (ed.), Pure and Applied Geophysics Special Issue, in press.

Moore, D.E., Summers, R., and Byerlee, J.D., in preparation. Strength, sliding behavior, and deformation textures of heated illite gouge at low and high pore pressures.

Sibson, R.H., 1986. Earthquakes and lineament infrastructure. Phil. Trans. R. Soc. Lond. A317: 63-79.

Stesky, R.M., Brace, W.F., Riley, D.K., and Robin, P.-Y. F., 1974. Friction in faulted rock at high temperature and pressure, Tectonophysics 23: 177-203.

Wallace, R.E., 1973. Surface fracture patterns along the San Andreas fault. In: R.L. Kovach and A. Nur (editors), Proc. Conference on Tectonic Problems of the San Andreas Fault System. School of Earth Sci., Stanford Univ., Stanford, CA, Geol. Sci. XIII: 248-250. 
Wallace, R.E., and Roth, E.F., 1967. Rates and patterns of progressive deformation. In: The Parkfield-Cholame California, Earthquakes of June-August 1966 -- Surface Geologic Effects, Water Resources Aspects, and Preliminary Seismic Data. U.S. Geol. Surv. Prof. Paper, 579: 23-40. 